\title{
Anthropogenic heathlands: disturbance ecologies and the social organisation of past super-resilient landscapes
}

\author{
Mette Løvschal ${ }^{*}$ (1) \\ * Aarhus University \& Moesgaard Museum, Højbjerg, Denmark (₫ lovschal@cas.au.dk)
}

\begin{abstract}
Focusing on the North European heathlands, this project investigates how self-organised communities in the past established large-scale grazing regimes. By considering changes in their particular forms of disturbance, exhaustion, autonomy and collaboration, the author envisages a new archaeology of emergent multispecies entanglements across a deep-time scale.
\end{abstract}

Keywords: Northern Europe, palaeoecology, heathlands, resilience, disturbance ecologies

\section{The prehistory of the North European heathlands}

More than 4000 years ago, small-scale agropastoral communities of Northern Europe began the first fire-based expansion and systematic management of naturally occurring heather ((L.) Hull Calluna vulgaris). Palaeoecological evidence reveals the incredible dynamics of these landscapes, covering thousands of hectares, in terms of their openness, land use, burning and grazing intensity, but also an exceptional longevity and capacity to re-establish right up to the nineteenth century (Figure 1). Across this timespan, pervasive societal and ecological transformations took place at multiple scales, including changes in population density, climate, exchange networks, mobility patterns, ideologies and infrastructure. In the face of these transformations, some heathlands transcended into shrublands or forest; in others, the return to heathlands transcended any competing landscape type.

Large-scale anthropogenic heath is an artificially sustained vegetational succession stage, with its retention dependent on disturbance. Left alone without frequent efforts to rejuvenate it, including burning and grazing, heathland will eventually turn into shrub and then forest (Figure 2). The palaeoecological evidence, however, demonstrates that heathland, which naturally is in a continuous state of regeneration into forest, was in some cases sustained for more than four millennia (Figure 3). This poses an intriguing puzzle regarding the capacity of such landscapes to rebound from extraction-oriented disturbances. What were the continuities and dynamics of these ecologies? Why did they become super-resilient in some areas, but not in others where abandonments, over-extraction and radical vegetation shifts can be detected? And how did grazing regimes endure despite radical internal and external changes? 


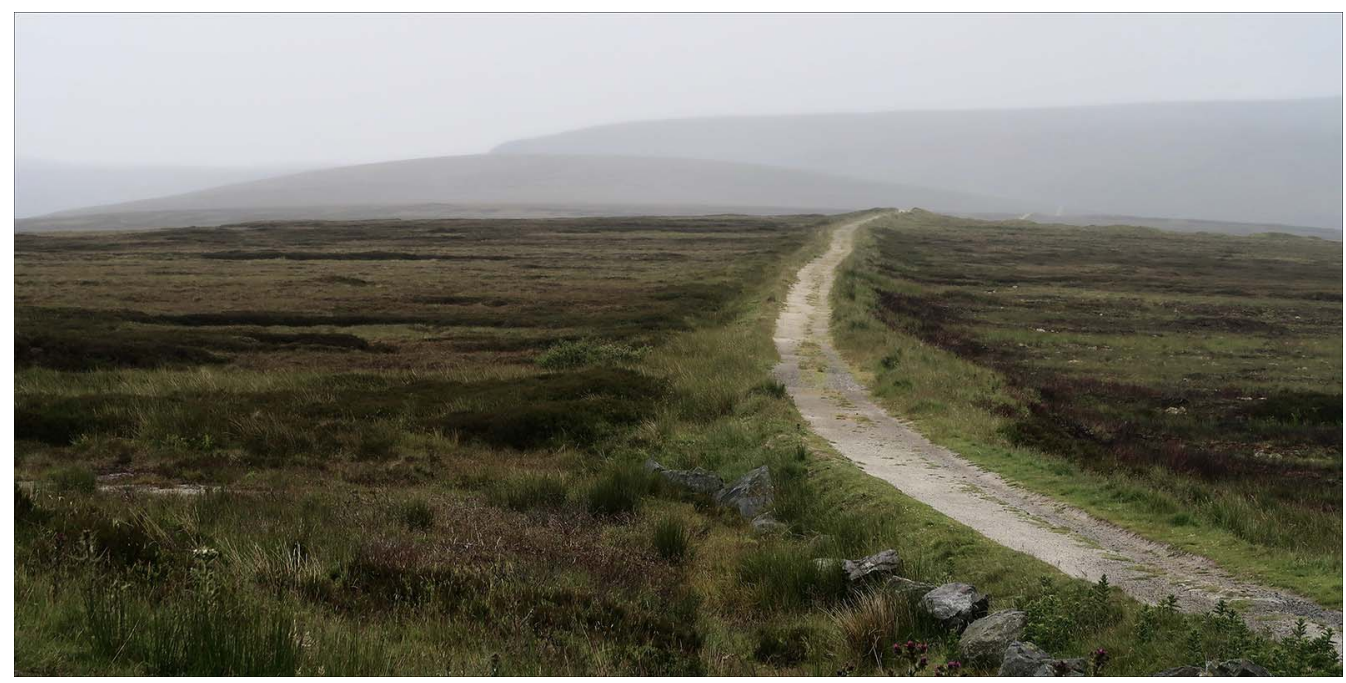

Figure 1. Trackway leading through a moorland (photograph by M. Lovschal).

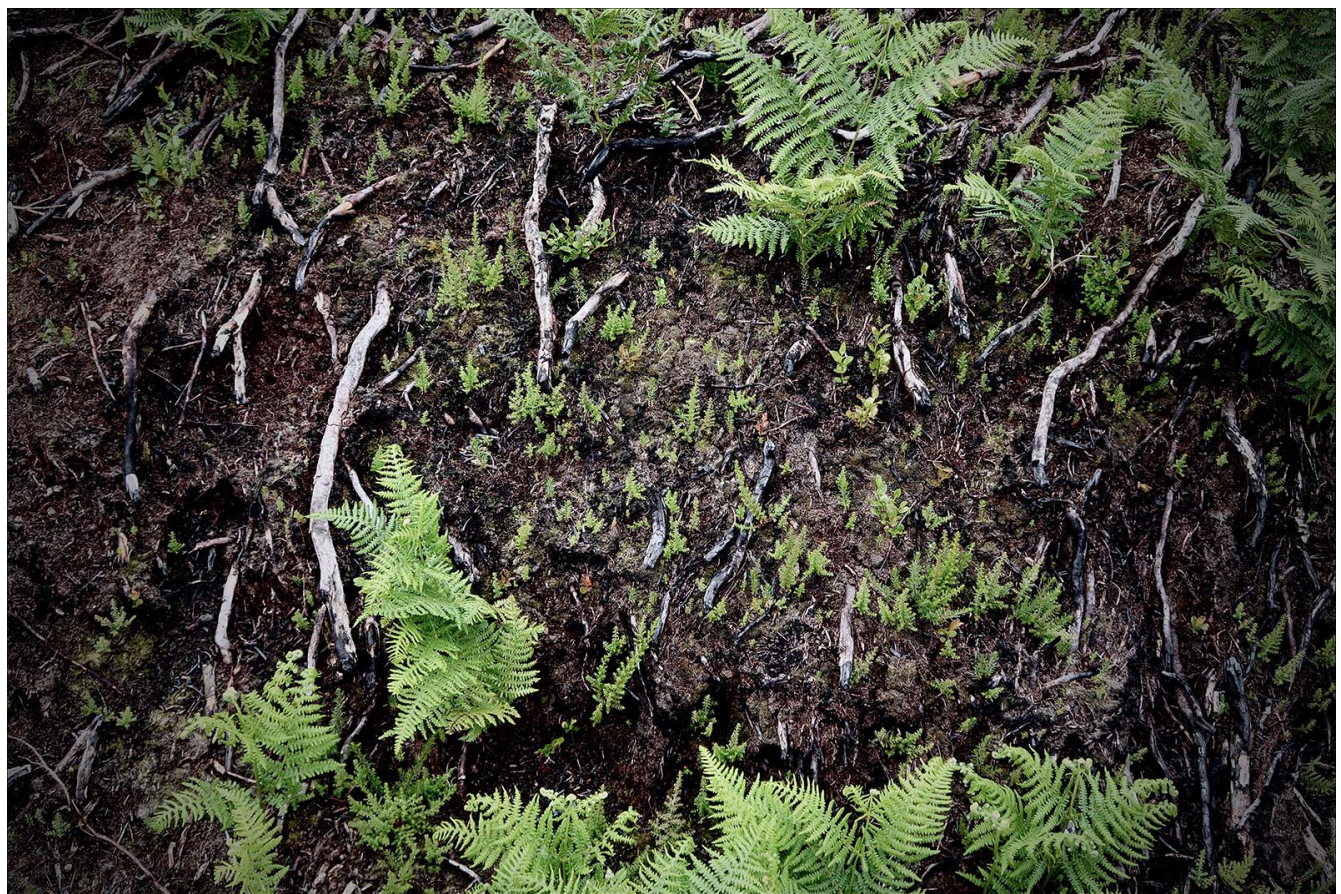

Figure 2. Newly burnt heathland surface where heather (and ferns) is reshooting (photograph by M. Løvschal).

\section{Resistance and collaboration}

The social organisation of anthropogenic Calluna heathlands has primarily been studied through the evidence of eighteenth-/nineteenth-century historical sources. At that time,

(C) The Author(s), 2021. Published by Cambridge University Press on behalf of Antiquity Publications Ltd. 


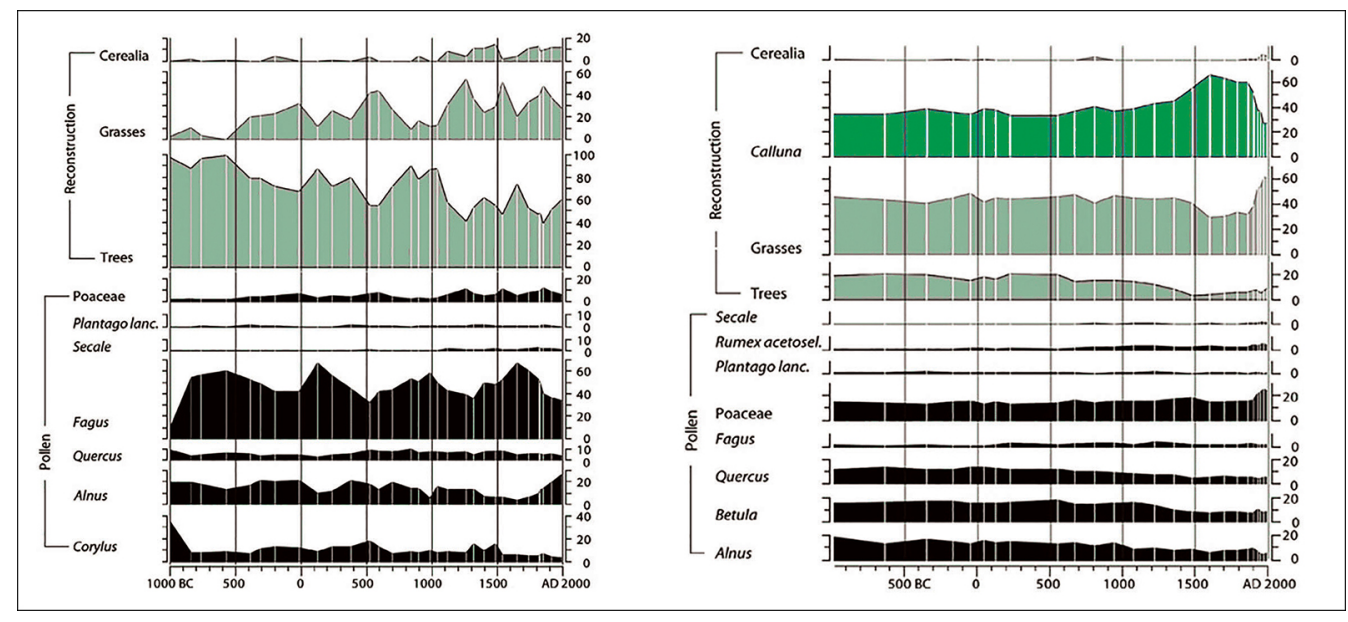

Figure 3. Landscape reconstruction algorithms showing how a heathland-dominated area (right) differs fundamentally from a forest-covered area (left) (after Nielsen \& Odgaard 2010).

heathland had become a central political pivot for the expansion of agriculture and was considered a kind of depleted, ungenerous, peripheral and residual landscape associated with primitive forms of economic organisation.

From an archaeological perspective, however, heathlands draw the contours of highly specialised landscape ecologies in which particular logics of collaboration and autonomy lodged themselves, with a unique capacity to persist or re-establish. For example, heathland settlements from Early Iron Age western Jutland deviated markedly from their neighbouring regions: they were sometimes organised as densely settled villages with extremely tight mutual regulation reflected in open forts, alignment, common entrances and fencesconcurrently with individual enclosures, storage spaces and livestock-keeping. Forms of organisation changed frequently with shifting site densities and phases of open and enclosed settlements, nucleation and abandonment, indicating widely held abilities to readjust. These observations invite further examination of how biosocial communities self-organise around particular disturbance ecologies and devise persistent structures of governance thereof.

An obvious launch pad is to consider theories of how self-governed institutions can organise in ways that outmatch the over-exploitation of common-pool resources and become essentially resilient. Following Ostrom (1990), commoning is a form of social organisation that emerges around the sharing of a resource depending on frequent coordination while reproducing particular institutions and economies. Importantly, ecologists have added a non-equilibrium-based understanding to ecological resilience, arguing that in fact low-stability systems can be very persistent (e.g. Gunderson \& Holling 2002). In this project, we focus on the specific - often hybrid-forms of commoning that emerge in the heathland conglomeration; and how forms of multispecies self-organisation, entanglements and becomings could help to expand the understanding of landscape commons, as biosocial configurations in which non-human others contribute to promoting deep-time dependencies. 


\section{Project design and methods}

The Anthropogenic Heathlands project (ANTHEA) is led by associate professor Mette Løvschal at Aarhus University and runs for a period of five years (2020-2025). Its chronological span covers $2800 \mathrm{BC}-\mathrm{AD} 1000$, with particular focus on the historical trajectories of heathland establishments and survival of large-scale reorganisations, including land allotment and de-/reforestation (Løvschal 2020). Seven case-study areas spanning from south-western Norway to south-western Britain will form shared geographic focal points for the project. Moreover, the project is based on four overlapping work packages investigating the underlying ecological (WP1), spatial (WP2), biosocial (WP3) and temporal (WP4) fabric of past grazing regimes.

First, we want to investigate the ecological fabric of heathland organisation, including the spectrum of variations in use- and grazing pressure, burning patterns and its sensitivity to abandonment. We will undertake a series of quantitative vegetation reconstructions by applying the landscape reconstruction algorithm and locally adaptive models of archaeological potential. This is supported with an extensive sampling and modelling of non-pollen palynomorphs, pollen, macrofossils and charcoal dust from sites across North-western Europe. Within one micro-region, Lake Skaansø (Denmark), we will carry out a targeted sampling of turf sediments from nearby barrows dating to $2800-1100 \mathrm{BC}$. As these turves would typically have been obtained in the vicinity of the barrows, with possibly exponential increase in distance from the barrow correlating with the subsequent construction stages, they add a unique level of detail in the micro-scale dynamics of past grazing land-use.

Second, we will investigate the spatial resilience of heathlands, including their geographical variation span in relation to, for example, geological conditions and land-use patterns. Detailed analyses of the archaeological record will allow us to differentiate between permanent habitation and other types of use-areas. We will quantify land-use changes based on site and off-site patterns and landscape modelling to make statistical predictions of 'empty areas' and potential heathland areas. We will also use existing palaeoecological data archives, historical and topographical maps to make quantitative reconstructions of past land-cover changes on a regional and local level for the seven case-study areas.

The third investigation will consider the biosocial resilience of heathland organisation, including the structures of collaborative governance and/or autonomy that made these multispecies communities able to sustain heathland livelihoods across millennia. What existing and emerging practices of care and extraction and forms of collaboration did they draw on? And what were the distributions of powers of existence across these landscapes? We will carry out detailed analyses of the organisational setups of settlements and funerary sites from excavation plans, including structures for resource sharing and storage, enclosures, traces of economic specialisation and the temporalities of heathland (rejuvenation) practices. We also investigate long-term trends and breaks in strategies for (re-)establishing pastoral communities. Moreover, we compare these findings with other contexts such as funerary and votive sites.

The fourth work package investigates the temporal fabric of heathland communities in order to answer the ultimate question pertaining to their unique capacity to endure or rebound. What is the spectrum of ecological, spatial and social variance under which deep-time heathland 
regimes can be identified? And when did oscillations lead to collapse with potentially successive re-establishments? WP4 is the overarching investigation that attempts to rewrite the cultural history of past anthropogenic heathlands. It explores a new suite of temporal investigation, modelling and complexity approaches, including scale-dependent Lyapunov exponent and adaptive fractal analysis to integrate the data from WP1-3, and to differentiate oscillations in governance strategies from real regime shifts. Moreover, data-intensive repositories will be included to map the earliest expansions of heathlands across Northern Europe and how these trajectories correspond with, for example, population densities and climate.

\section{Heathlands of the Anthropocene}

Some of the world's largest common grazing regimes such as the Northern Serengeti plain, the steppes of East and Central Europe and Mongolia have recently become subjected to rapidly expanding land privatisation, enclosure and degradation. Calluna heathlands are similarly quickly degrading across Northern Europe at present; 85-95 per cent have eroded within the last two centuries (Figure 4). Due to changed maintenance forms, eutrophication and high levels of atmospheric pollution, they will most likely disappear almost entirely within the next generation. But whereas there exists vast knowledge about how commons collapse, we have limited understanding about how collaborative grazing regimes arise and how the decline of common lands can be reversed.

Anthropogenic heathlands are uniquely dependent on, and able to spontaneously form connections and dependencies with, others. They can also reveal humans and non-humans in mutually interlocking sequences of exhaustion and resurgence. Their historical trajectories provide a deep-time image of Anthropocene ecologies, as slow, non-mobile and spacedemanding landscapes, which cannot be radically maximised or transplanted, providing a counter image to the plantation. Through a deep-time archaeologically informed approach to such ecologies, we hope to add vital new knowledge of emergent multispecies entanglements and resilient forms of land-use organisation.

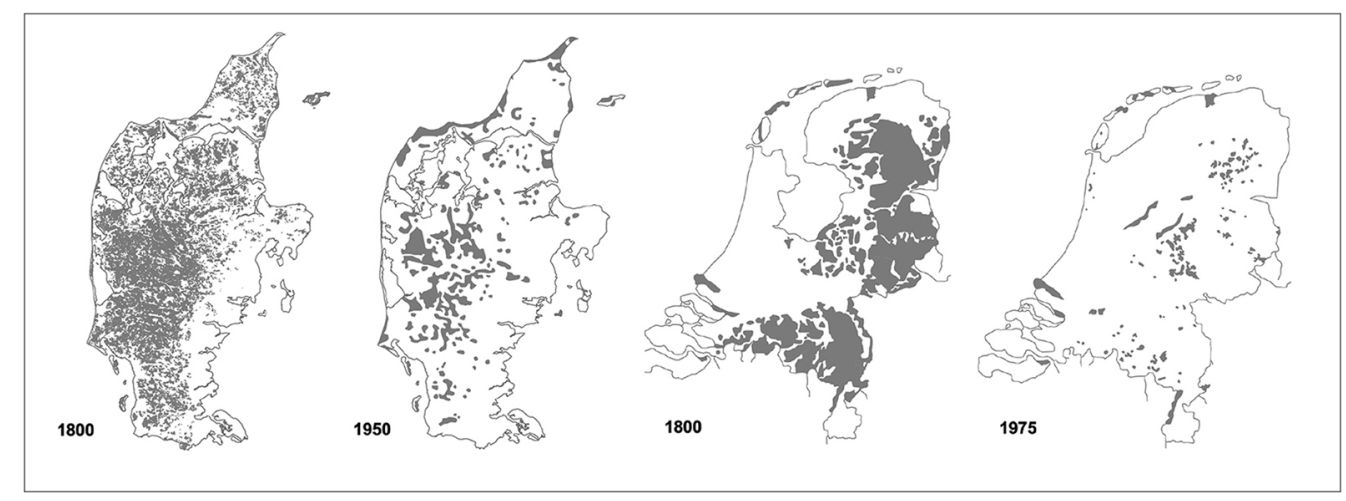

Figure 4. The radically decreasing distribution of heathlands in the period between c. 1800 and 1950/1975, in present day Denmark (left) and the Netherlands (right) (after Geografisk Institut ved Kobenhavns Universitet and Diemont 1996).

(C) The Author(s), 2021. Published by Cambridge University Press on behalf of Antiquity Publications Ltd. 


\section{Funding statement}

The project has received funding from the European Research Council under the European Union's Horizon 2020 research and innovation programme (grant agreement 853356).

\section{References}

Diemont, W.H. 1996. Survival of Dutch heathlands. Wageningen: Institute for Forestry and Nature Research.

Gunderson, L.H. \& C.S. Holling (ed.). 2002. Panarchy: understanding transformations in human and natural systems. Washington, D.C.: Island Press.

Løvschal, M. 2020. The logics of enclosure: deep-time trajectories in the spread of land tenure boundaries in late prehistoric Northern Europe. Journal of the Royal Anthropological Institute 26: 365-88.

https://doi.org/10.1111/1467-9655.13252
Nielsen, A.B. \& B.V. OdgaArd. 2010. Quantitative landscape dynamics in Denmark through the last three millennia based on the landscape reconstruction algorithm approach. Vegetation History and Archaeobotany 19: 375-87. https://doi.org/10.1007/s00334-010-0249-z

Ostrom, E. 1990. Governing the commons: the evolution of institutions for collective action. Cambridge: Cambridge University Press.

https://doi.org/10.1017/CBO9780511807763 